\title{
CUENCA DEL CEBOLLATí: Nuestro territorio, un proyecto compartido. Formulación de las bases de ordenamiento territorial y desarrollo sostenible
}

Arq. Susana Martínez, Arq. Alessandra Benevides, Arq. Alejandro Falkenstein, Arq. Alma Varela, Dra. Matilde Saravia

\section{RESUMEN}

Este documento presenta los resultados de un trabajo interdisciplinar ${ }^{1}$ de carácter analítico-propositivo realizado en el ámbito de la Maestría de Ordenamiento Territorial y Desarrollo Urbano (Facultad de Arquitectura, Universidad de la República ). Relata una experiencia que coordinó esfuerzos y acciones entre el ámbito académico, el gobierno nacional y los gobiernos locales.

El trabajo toma como unidad de estudio y propuesta el territorio de la Cuenca del Río Cebollatí, y tiene como objetivo formular las bases de ordenamiento territorial que habiliten la preservación de los recursos naturales y culturales de la zona, así como la revalorización de los elementos de identidad, sus tradiciones. Está desarrollado en el marco de la Ley de Ordenamiento territorial y Desarrollo Sostenible que definió nuevas pautas y roles institucionales en la temática. En este contexto, la construcción de políticas de ordenamiento territorial para la Cuenca implicó un proceso participativo, como una sacudida de tradiciones, voces y sensaciones, novedoso en Uruguay.

Palabras clave: Ordenamiento territorial, cuenca, paisajes culturales.

${ }^{1}$ Además de los autores del artículo, los integrantes del equipo de trabajo fueron los maestrandos. Natalia Barindelli, el doctor Jorge Álvarez; los arquitectos Álvaro Cayón, Raul Vallés, José Freitas, Marcelo Roux, María Fernanda Algorta, Cecilia Mc. Alister, Marcos Castaigns y Gonzalo Balarini, y el ingeniero Maria Fernanda Algorta, Cecilia Mc. Alister, Marcos Castaigns y Gonzalo Balarini, y el ingeniero
agrimensor Jorge Franco. El trabajo de taller fue coordinado por la magíster Mercedes Medina con la participación del director académico de la Maestría, el arquitecto Carlos Acuña. 


\section{ID INVESTIGACIONES}

\section{ABSTRACT}

This paper presents the results of an interdisciplinary analytical-propositional work that was made within the scope of Planning and Urban Development Master Studies (School of Architecture, Udelar). It shows a coordinated experience between the academia, national and local governments.

The work takes as its unit of analysis and proposal the Cebollatí Basin, and its aims is to formulate the planning bases that enables the preservation of its natural and cultural resources as well as the appreciation of its identity and traditions. The work is developed within the scope of Planning and Sustainable Development Law that defines new guidelines and institutional roles in this subject. In this context, the construction of planning policies for the Basin involved a participatory process, like a jolt of traditions, voices and feelings, which is new in Uruguay.

Key words: Land Planning/ basin/ cultural landscape

\section{INTRODUCCIÓN}

Esta experiencia involucró múltiples actores en una circunstancia político administrativa trascendental para el país, marcada por la reciente sanción de la ley de Ordenamiento Territorial y Desarrollo Sostenible (LOTDS) y la Ley de Descentralización y Participación Ciudadana en proceso de aprobación. El compromiso representó un triple desafío para el equipo de trabajo.

Desde el punto de vista técnico, el primer desafío consistió en desarrollar las bases para la formulación de uno de los instrumentos de planificación consagrados en la LOTDS, las directrices para el Ordenamiento Territorial de la Cuenca del Cebollatí, y sentar las bases para la formulación de los Planes de 


\section{ID INVESTIGACIONES}

las localidades vinculadas a la Cuenca $^{2}$. Todo ello conforme a un proceso participativo, de manera que el resultado de la propuesta implicara un proyecto compartido entre sus habitantes. Para eso, desarrollamos talleres -ámbitos de encuentro e intercambio- en los que participaron actores locales en las microregiones y se compartieron y tomaron de visiones y proyectos territoriales con arraigo y de construcción local.

El segundo desafío se planteó en el ámbito territorial. En el entorno geográfico de la cuenca que comparten cuatro departamentos ${ }^{3}$, se desarrolla un mosaico de paisajes y realidades diferentes: sierra, valles, lomadas sedimentarias y llanuras donde se destacan los humedales sobre la costa de la Laguna Merín. Si bien la cuenca es una unidad geográfica de lectura fundamental para el manejo de los recursos hídricos, verificamos otras lógicas territoriales que se superponen y que se componen de sistemas urbano-territoriales vinculados a otras realidades geográficas. El reconocimiento de estas situaciones implicó la incorporación de fracciones de territorios situadas fuera de los límites estrictos de la Cuenca.

El tercer desafío, en el ámbito académico, consistió en la búsqueda de respuestas en un equipo técnico interdisciplinario. Se aportaron diferentes experiencias y modalidades de trabajos que obligaron a la construcción de estrategias para desarrollar una construcción metodológica colectiva.

\footnotetext{
${ }^{2}$ Las localidades incluidas en el convenio fueron Rincón, Arrozal 33, Vergara, General José Enrique Martínez, Cebollatí, Villa Passano, Lascano, José Pedro Varela, María Albina e Isla Patrulla, a las que el equipo de trabajo incorporó las de Mendizábal/ El Oro, Picada de Techera, Puntas del Parao y Paso Averías durante el proceso de elaboración.

${ }^{3}$ División político administrativas de la República Oriental del Uruguay.
} 


\section{ID I N VESTIG AC I O NES}

\section{METODOLOGÍA DE TRABAJO}

En primera instancia se debatieron y consensuaron las bases conceptuales ${ }^{4}$ del trabajo: el abordaje del territorio; la construcción del proceso participativo; la interpretación del marco jurídico aplicable; y el contenido de los productos a ser generados y los métodos de presentación de los resultados a los actores locales.

En segundo lugar se recogió la información básica a escala de la cuenca y de los sistemas urbano-territoriales previamente definidos y se confeccionó un inventario de recursos naturales, institucionales, económicos y sociales existentes en el territorio, así como también de documentos y estudios preexistentes.

En tercer lugar se realizaron talleres territoriales convocados por las administraciones locales ${ }^{5}$, en los que participaron instituciones, organizaciones y actores sociales de las localidades. En ellos se verificó la información básica y las hipótesis de trabajo, y se plantearon propuestas en conjunto con los actores locales ${ }^{6}$.

En relación a las escalas territoriales utilizadas, el trabajo se define desde un enfoque multiescalar ${ }^{7}$ abordando las escalas de la cuenca, de las microrregiones y de las localidades. En función de esa realidad de múltiples escalas, el equipo multidisciplinar de trabajo se coordinó y organizó en sub-

\footnotetext{
${ }^{4}$ El trabajo en la Cuenca del Cebollatí retoma el enfoque metodológico implementado por el Instituto de Teoría de la Arquitectura y Urbanismo (ITU-Facultad de Arquitectura-UdelaR) en el Sistema del Planificación Participativa del Departamento de Maldonado, con Talleres Territoriales para la definición de Directrices y Agendas de Proyectos.

${ }_{6}^{5}$ Que son las juntas locales, antecedentes de las actuales alcaldías

${ }^{6}$ En el primer taller se inició el proceso de construcción del proyecto colectivo, el segundo taller permitió ajustar las propuestas que surgieron a partir de la instancia anterior y verificar la información incorporada en la etapa anterior, y en el tercer taller se presentaron las directrices generales de Ordenamiento Territorial y las propuestas que surgieron del proyecto colectivo.

7 Territorial y las propuestas que surgieron del proyecto colectivo.
En particular se identifica: 0) Escala Cuenca; 1) Microrregión Vergara, Rincón, El Oro y Arrozal 33; 2) En particular se identifica: 0) Escala Cuenca; 1) Microrregión Vergara, Rincón, El Oro y Arrozal 33; 2)
Microrregión La Charqueada, Cebollatí, Passano y Picada de Techera; 3) Microrregión Lascano, Paso Averías, José P. Varela y María Albina; 4) Microrregión Isla Patrulla, Quebrada de los Cuervos y Puntas del Parao.
} 


\section{ID_INVESTIGACIONES}

grupos desde la Maestría. Cuatro de ellos abordaron las microrregiones delimitadas, y un quinto equipo elaboró la propuesta a escala de la Cuenca.

Este trabajo considera el territorio como un sistema complejo, en el que hay que contemplar, además del medio físico natural y construido, el espacio habitado -ámbito de asentamientos y de interacción social-, el espacio económico -ámbito de producción- y el espacio político -ámbito de gobierno. El territorio es, además, un proceso dinámico y auto-organizado, una construcción de la interacción material y simbólica entre sociedad, espacio y tiempo.

Entendiendo al territorio como una construcción humana nos abocamos a indagar el patrimonio cultural de la Cuenca, esto es la huella del trabajo de sus habitantes, como un texto que se puede escribir e interpretar 8

\section{EL OBJETO DE ESTUDIO: LA CUENCA}

La cuenca del Cebollatí, en la Región de la laguna Merín ${ }^{9}$, comparte con otros tributarios como los ríos Yaguarón y Tacuarí, una densa red fluvial y un lento drenaje por humedales y esteros ${ }^{10}$ Actúa como un operador sistémico ${ }^{11}$ dentro del cual se distinguen una amplia variedad de suelos y paisajes, conformando sierras, valles, lomadas sedimentarias y llanuras.

El uso del suelo corresponde predominantemente a la explotación agropecuaria. En la cuenca alta y media prevalece la actividad ganadera, aunque en los últimos años se ha producido un avance importante de la forestación, además de otros cultivos como los olivos, la soja y el trigo. También se han empezado a desarrollar algunas actividades vinculadas al

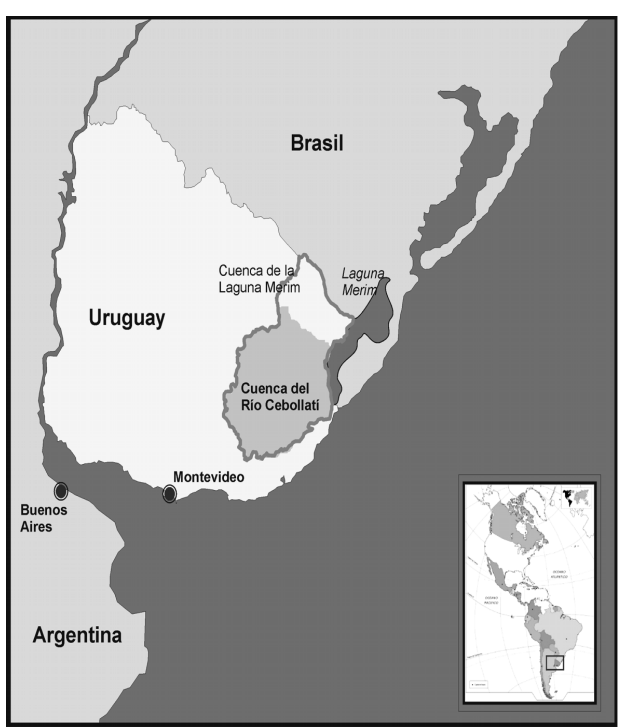

Cuenca del Cebollatí en la región

${ }^{8}$ Sabaté, Joaquin. Paisajes culturales y desarrollo local ¿Alta costura o prêt a porter?, Revista Labor e Engenho $\mathrm{N}^{\circ} 1$

${ }^{9}$ La extensión de la Cuenca binacional de la Laguna Merín es de $62.250 \mathrm{~km}^{2}$

${ }^{10}$ La extensión de la Cuenca binacional de la Laguna Merín es de 62.250
11

${ }^{11}$ Cualquier alteración cualitativa y/o cuantitativa producida en la cabecera de cuenca incidirá tanto en el funcionamiento global como en el de sus subsistemas componentes. 
ID_INVESTIGACIONES

turismo. En la cuenca baja predomina la actividad agrícola-ganadera, donde la tierra es sometida a un sistema de rotación arroz-pasturas. El uso del agua provoca tensiones entre productores, otros actores locales y el Estado. En esta zona, se verifican más de 30 tomas de agua sobre ríos y arroyos, así como represas construidas con el fin de promover el cultivo de arroz. Además, se apuesta por la navegabilidad del Río Cebollatì y hay una propuesta de hidrovía, algo de turismo y pesca artesanal.

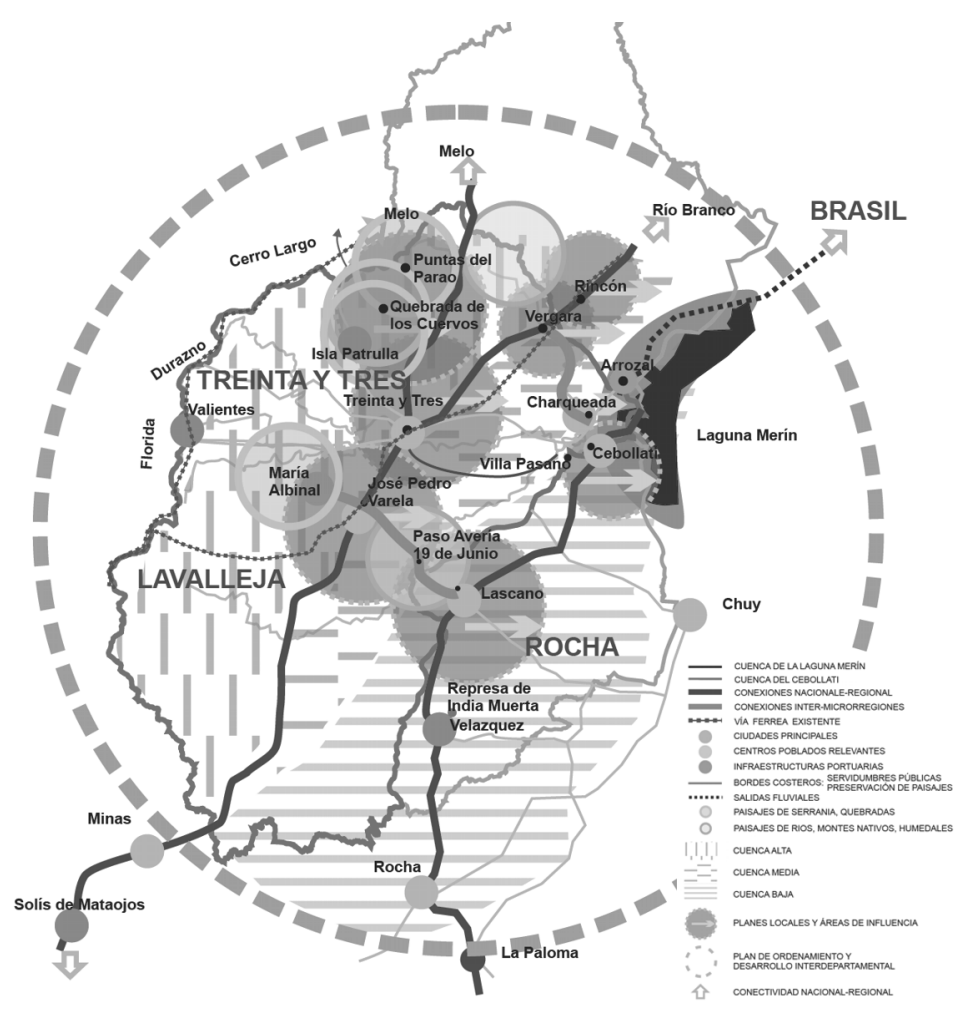

La cuenca del Cebollatí y principales localidades 


\section{ID INVESTIGACIONES}

A mediados del siglo $X X$ se realizaron importantes obras de drenaje y riego con la intención de recuperar tierras para la producción agropecuaria. Se modifico así la realidad hídrica de la región, dando lugar a un paisaje fuertemente antropizado. Con la actividad económica productiva convive además, un patrimonio arqueológico y natural, amenazado por el avance del área cultivada.

La superficie de suelo ocupada por asentamientos urbanos es insignificante en relación al predominio del suelo rural, con una muy baja densidad de habitantes por hectárea. ${ }^{12}$ El proceso de explotación del cultivo de arroz asociado al desarrollo de la producción agrícola, dio origen a pueblos organizados en forma semiautónoma en el territorio, vinculados exclusivamente a la producción y a la industrialización del arroz.

Las localidades se distribuyen en función de las principales vías de comunicación y del sistema en red de caminos internos del departamento, que vinculan los principales centros poblados.

\section{Unidades de trabajo para el abordaje del territorio: las microrregiones}

Para la realización del análisis territorial se definieron cuatro microrregiones. Estas unidades constituyen recortes territoriales menores al interior de la cuenca que no necesariamente coinciden con los límites políticoadministrativos establecidos y que abarcan de 3 a 5 localidades urbanas.

\footnotetext{
${ }^{12}$ Según datos del Censo 2004, entre las localidades mayores se encuentran: Cebollatí (Departamento de Rocha), con 1606 habitantes.

José Pedro Varela (Departamento de Lavalleja), con 5.332 habitantes.

Lascano (Departamento de Rocha), con 6.994 habitantes

Estación Rincón (Departamento de Treinta y Tres) cuenta con 742 habitantes.

Treinta y Tres, con 29.711 habitantes.

Vergara (Departamento de Treinta y Tres), con 3.986 habitantes.

Otras localidades de menor población son: EI Oro (100 habitantes); La Charqueada (697 habitantes): Arrozal 33 (400 habitantes); María Albina (120 habitantes); Isla Patrulla (200 habitantes); Villa Pasano (50 habitantes)
} 


\section{ID_INVESTIGACIONES}

El perímetro definido para cada microrregión responde a un comportamiento diferencial (productivo, de paisaje, ecosistémico, socio-productivo, de enlace, etc.), así como al reconocimiento de los pobladores de un territorio sentido como particular y propio. De la superposición de estas unidades temáticas se construyen los polígonos de distintas extensiones y proporciones.

Los límites de las microrregiones consideran, además de los vínculos existentes entre los distintos centros poblados (formales o no), factores históricos y características físicas, culturales y productivas. Este recorte territorial fue una propuesta tentativa del equipo de trabajo, posteriormente sometida a verificación, luego de sucesivos intercambios con actores locales, en etapas posteriores.

La propuesta de trabajo se construye a través de un abordaje transversal de las diferentes escalas -localidades, micro regiones y cuenca- en que se realiza la lectura territorial, haciendo referencia al nivel de incidencia en cada dimensión. $^{13}$

Tras las fases de delimitación, caracterización y diagnóstico, para cada microrregión se define una marca/eslogan con el objetivo de sintetizar la vocación y la identidad manifiesta de cada territorio. A través del eslogan, se conceptualizan aquellos aspectos considerados identitarios de cada territorio, así como una visión del futuro deseable de alcanzar. La marca es una herramienta eficaz, no sólo para la gestión de la producción, sino para la puesta en valor de los paisajes culturales.

La gestión del territorio desde esta concepción, trasciende los ámbitos administrativos, motiva la creación de ámbitos de encuentro para los diversos actores locales y refuerza su autoestima. En definitiva, promueve el fortalecimiento de la gestión del territorio, al poner en valor la especificidad y

\footnotetext{
${ }^{13}$ Dimensiones planteadas: Físico-espacial, Socioeconómica, Eco-sistémica y Jurídico-Institucional.
} 
diversidad de las comunidades locales, a través de sus elementos de identidad, cultura y de sus tradiciones. Asimismo, brinda un espacio para el manejo de conflictos territoriales y el aprovechamiento de oportunidades, al fortalecerlos y dotarlos de sentido económico.

Microrregión 1: Localidades de Rincón, Vergara, El Oro, Arrozal 33: "Llanos, taipas y molinos"

Territorio llano, que se caracteriza por la presencia de centros poblados de variada configuración física, en un sistema incipiente de red, con estructuras urbanas no consolidadas, asentamientos de baja densidad ${ }^{14}$ algunos de ellos vinculados exclusivamente a enclaves productivos, como a la producción e industrialización del arroz.

Un factor común es el predominio de los programas de ejecución de viviendas de MEVIR ${ }^{15}$ como el mayor impacto en un contexto de baja densidad por habitante y vivienda por hectárea. Las localidades de Rincón y El Oro son claros ejemplos de ello.

El territorio es predominantemente rural, básicamente arrocero-ganadero, lo que ha generado una cierta especialización en la población. Sin embargo, muchos de los espacios dedicados a esta producción están sufriendo profundas transformaciones, debido fundamentalmente, a la intensificación de la actividad forestal, la presión que ejerce la soja y los exóticos cultivos de olivares.

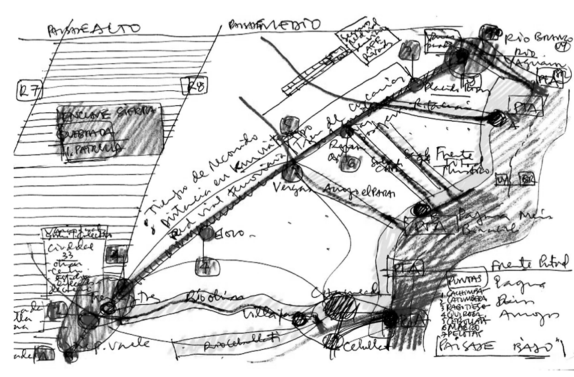

MODEO DE DOBLE PAR Y COMPLEMENTARIEDAD ENTRE VERGARA / RINCON R18 / ViA FERREA

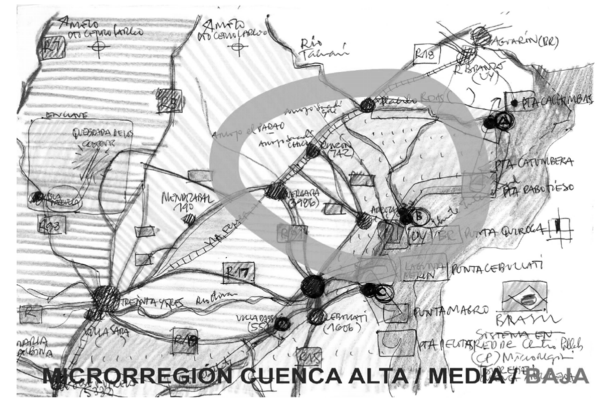

Propuestas para la microrregión 1

\footnotetext{
${ }^{14}$ La excepción es Vergara con aproximadamente 4.000 habitantes, segunda ciudad del departamento de Treinta y Tres.

MEVIR se constituye bajo La Ley № 13.640 del 26.12.67, que determina la creación del Fondo para la Erradicación de la Vivienda Rural Insalubre y tiene por cometido la construcción de viviendas higiénicas que sustituyan las habitaciones insalubres existentes en el medio rural y aledaños de las poblaciones urbanas del interior.
} 


\section{ID_INVESTIGACIONES}

"Llanos, taipas y molinos": Llano, un territorio horizontal y tranquilo, la geografía litoral más característica del este del territorio uruguayo. En este espacio destacan los recursos hídricos, ríos y arroyos que significan corredores biológicos, piezas fundamentales de la lógica que domina al llano, en tanto espacio eco-sistémico, socio-cultural y económico-productivo de altísimo valor patrimonial. Las taipas sugieren la acción proactiva, el saber hacer de la cultura del habitante del lugar en su intensa relación con el suelo, diálogo de mutuas conveniencias y elegantes trazos formales. Finalmente, los molinos, son entendidos como herramientas de procesos de transformación, económicosocial, físico-espacial, determinantes fundamentales del desarrollo local

Esta microrregión es entendida como un espacio de proximidad, de relaciones en horizontal sobre el soporte geográfico singular del llano. Se propone activar la complementariedad de sus centros poblados, dotándolos de equipamiento urbano de diverso alcance en un modelo territorial promotor de mejoras en la calidad de vida. Entre ellos destacan las propuestas en la franja costera de laguna Merín, espacio ideal de enlace internacional.

Microrregión 2: localidades de La Charqueada, Cebollatí, Villa Passano y Picada de Techera: "Portal de la laguna Merín"

La Microrregión se conforma por sectores de los departamentos de Treinta y Tres y Rocha, con centros administrativos y de servicios en las localidades de La Charqueada y Cebollatí. La definición de la microrregión responde a su comportamiento diferencial, y al reconocimiento de sus pobladores de un territorio particular, sentido como propio.

Esta pieza territorial se encuentra en la desembocadura del río Cebollatí en la Laguna Merín. Es un territorio fuertemente antropizado por la producción agrícola-ganadera que implica la alteración del sistema hídrico y la modificación
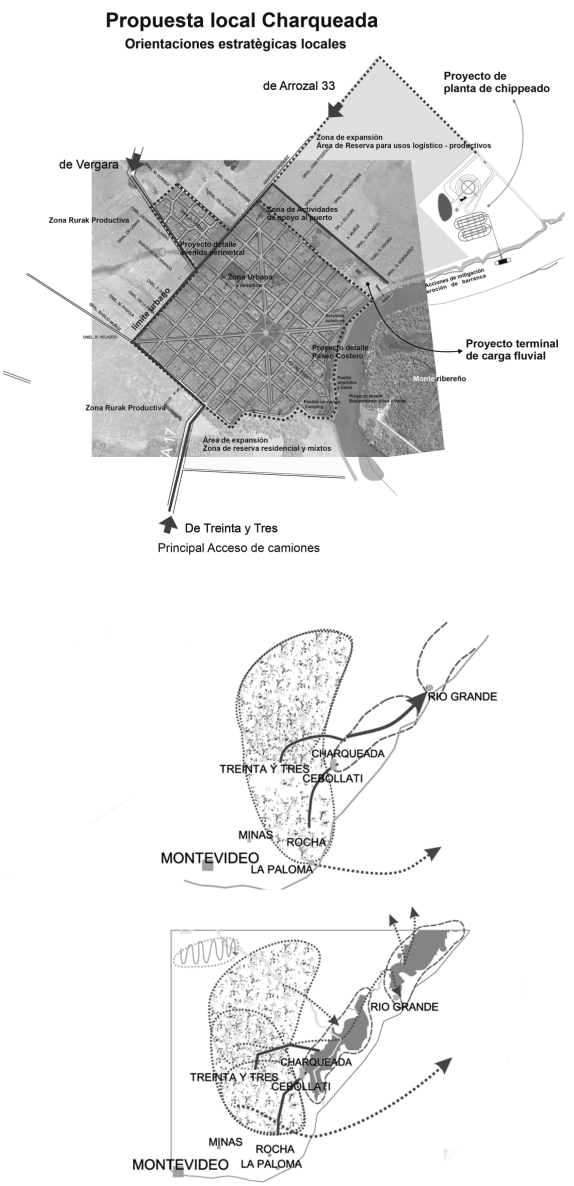

Propuestas para la microrregión 2 


\section{ID_INVESTIGACIONES}

de la estructura ambiental. El agua, principal recurso para la producción arrocera, motivo del asentamiento de la producción en la cuenca, es también un valioso recurso paisajístico y ambiental. Asimismo, la presencia del bosque ribereño en los cursos de agua y la costa sobre la laguna con sus islas, esteros y humedales, evidencia el conflicto entre el desarrollo del uso del suelo agrícola y las áreas de valor paisajístico y ambiental.

Se reconoce un sistema urbano con vinculaciones múltiples, con localidades mayores $^{16}$ (bien equipadas con servicios e infraestructura a nivel local) y una serie de localidades dispersas, de menor escala y asociadas a la producción agrícola $^{17}$ En los últimos años las pequeñas localidades decrecen en población, al tiempo que aumentan las mayores.

Las dos mayores, La Charqueada y Cebollatí, se localizan estratégicamente como nodo y puente de conectividad entre los departamentos de Rocha y Treinta y Tres, pero también como portal a la laguna Merín y, en este sentido, a la hidrovía Este.

Además de la producción agrícola-ganadera (principalmente arrocera), se dan una serie de actividades económicas complementarias (molinos, secaderos, logística relacionada al agua) y otras que muestran incipientes posibilidades de diversificación productiva, como la pesca, la logística asociada al futuro puerto en La Charqueada y el desarrollo de la actividad turística en ambas localidades asociadas al río y la laguna.

"Portal de la laguna Merín": Se propone la consolidación de un esquema de desarrollo productivo propio y sostenible, que permita superar las vulnerabilidades de los excepcionales valores ambientales y de su población, asegurando una mejor calidad de vida. Su potencial productivo futuro -arroz y

\footnotetext{
${ }^{16}$ La Charqueada y Cebollatí, ambas con menos de 1500 hab.

7 Villa Passano, Picada de Techera, San Luis al medio, CIPA Olimar, CIPA La Paz, entre otras.
} 
ganadería- diversificado e integrado con otras actividades productivas, relacionadas fundamentalmente con la pesca, la conservación-protección y aprovechamiento de las áreas de valor ambiental, el turismo y la logística, respetuosas todas ellas con los valores ambientales de la unidad paisajística río Cebollatí-Laguna Merín.

Microrregión 3: Localidades de Lascano, Paso Averías, José Pedro Varela y María Albina: "Arroz, agua, sierra y tradiciones"

Compuesta por un territorio que abarca tres departamentos, esta microrregión tiene como núcleo el eje de localidades urbanas de Lascano, Paso Averías, José Pedro Varela y María Albina. El contexto de su ubicación en un territorio administrado por múltiples actores políticos, constituye sin duda un desafío mayor a la hora de proponer proyectos comunes.

En lo que se refiere a sus características geográficas, la multiplicidad igualmente es relevante. Incluye en su territorio áreas que representan los sectores bajos (altitudes de 0 a 50 metros), medianos (51 a 150) y altos (151 a 30 metros) de la cuenca, lo que le confiere un carácter único en el contexto del área de estudio. La riqueza geomorfológica de este territorio permite observar una particular complejidad paisajística, y productiva principalmente cuando se comparan los extremos Este (Ilanuras y planicies) y Oeste (sistema de sierras).

La producción se orienta mayoritariamente hacia las actividades agropecuarias, con significativo destaque del cultivo de arroz y de ganadería intensiva en el área de planicie del cauce bajo del río Cebollatí, a la altura de Lascano y de ganadería extensiva en la zona serrana de María Albina. Completando el escenario productivo de la microrregión, en los últimos años es posible observar proyectos embrionarios de lechería, producción de aceite de oliva y minería, principalmente en la zona de Lascano.

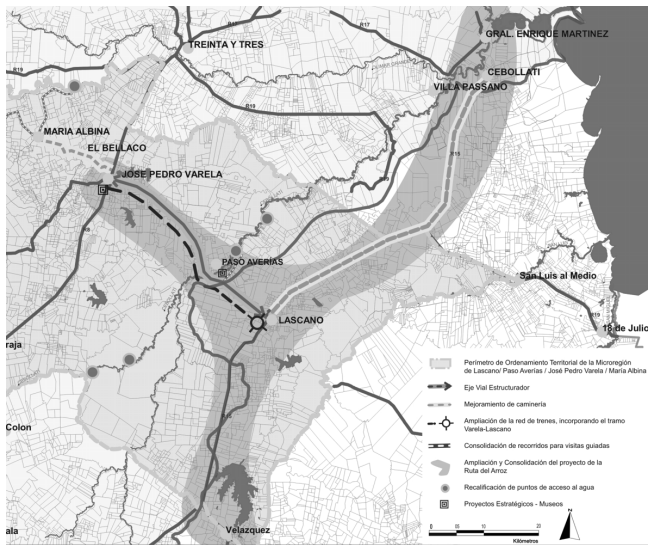

Propuestas para la microrregión 3 


\section{ID_INVESTIGACIONES}

El eje de localidades se entiende como el espacio organizador, "columna vertebral" de un sistema dónde coexisten diversidad de actividades y paisajes, pudiendo llegar a complementarse y potenciarse a través de la idea de un proyecto integral que haga de elemento articulador y motor del desarrollo. En este contexto, cabe a las ciudades de Lascano y Varela el rol de importantes centros de procesamiento, almacenamiento y distribución del arroz.

Al mismo tiempo, la forestación, realizada principalmente con inversiones de capitales externos siendo destinada principalmente a la industria papelera, destaca como producción que avanza a partir del norte del Departamento de Lavalleja, en dirección a la zona serrana de María Albina.

Se entiende que la Microrregión contiene particularidades e identidades comunes, capaces de actuar como disparadores, para elaborar actividades alternativas que permitan desarrollar propuestas locales no convencionales, como por ejemplo, la implementación de circuitos histórico-culturales con destinos educativos y turísticos.

"Arroz, agua, sierra y tradiciones": La estrategia de desarrollo dependerá de la articulación producción-desarrollo turístico, actividades que se potencian a partir de la complementariedad y valorización de la diversidad del paisaje natural, serranía-río y de una cultura e historia productiva propia de la microrregión.

De esta manera se incorpora al eslogan, la presencia de cuatro componentes relevantes en todo el territorio: el arroz como expresión de la principal actividad productiva asociada al desarrollo económico de la microrregión; el agua, elemento esencial para la producción y protagonista de atractivos paisajes; las serranías todo lo cual en su conjunto esta intrínsicamente vinculado a las tradiciones e idiosincrasia de sus pobladores. Los distintos elementos expresan diversidad, al mismo tiempo que la necesaria unidad a fortalecer. 
Diversidad que se lee como fortaleza, donde a la matriz de desarrollo tradicional arrocera- ganadera, se suman las posibilidades de generar servicios complementarios de la producción y un potencial desarrollo factible a través de emprendimientos de base agro-turística con variadas características.

Microrregión 4: Localidades de Isla Patrulla, Puntas del Parao y Quebrada de los Cuervos: "Islas en serranías"

Constituye una vasta zona rural, de producción históricamente ganadera, marcada en la actualidad por un crecimiento de la actividad forestal. También coexisten en el área numerosas prospecciones mineras, y algunos establecimientos turísticos.

El polígono que compone esta microrregión se encuentra cubierto por una considerable red de caminería menor, que se completa con senderos y servidumbres vinculados a la administración de las propiedades productivas y a espacios turísticos.

La escasa población es dispersa o afincada en pequeños parajes cuyas denominaciones responden a relatos de fuerte impronta local.

Exhibe una cadena de cerros por donde discurren cursos de agua entre afloramientos rocosos y matas de vegetación arborescente. Las quebradas constituyen una característica distintiva, y generan un microclima donde se produce una vegetación más densa y variada que la del monte ribereño, conformando corredores biológicos de los diferentes tipos de ambientes serranos del Uruguay y de Río Grande do Sul. Posee atributos paisajísticos bien determinados y un gran potencial, asociado al paisaje serrano, que aloja episodios particulares, de gran belleza natural, como la Quebrada de los
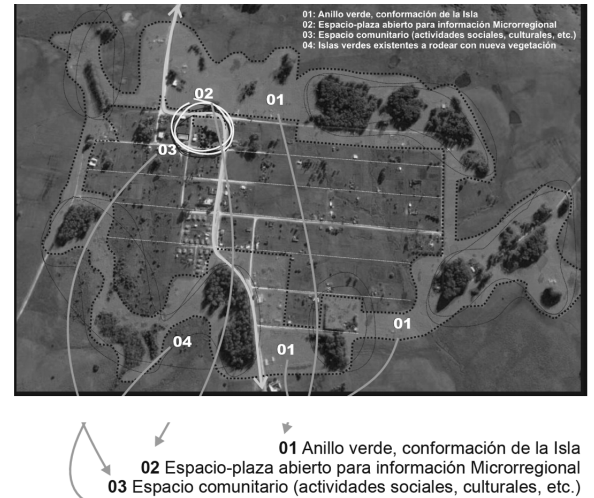
$\underset{\mathrm{N}}{\mathrm{O} \text { Espacio comunitario (actividades sociales, culturales, etc.) }} \mathrm{04}$ Isla verde existentes a rodear con nueva vegetación

Propuestas para la microrregión 4 
ID_I N VESTIG AC I O NES

Cuervos, primera área del país que ingresa como "Paisaje Natural Protegido" al Sistema Nacional, y otros de valor similar.

"Islas en las serranías": La región se caracteriza por la presencia de pequeñas poblaciones localizadas en las sierras, en las cabeceras de cuenca, donde se reconoce la necesidad de preservar el paisaje natural específico de la microrregión, a través de una zonificación que defina los usos del suelo prioritarios.

El modelo de territorio deberá estar basado, caracterizado e identificado por la protección y manejo responsable de los recursos naturales, rurales y de paisaje. Se promueve el desarrollo sostenido de la actividad agropecuaria tradicional en la zona; articulando este desarrollo, con una actividad de disfrute del ocio, vinculada al ecoturismo, y a la reconversión del monte natural como fuente de recursos para cultivo, producción y comercialización de especies nativas.

\section{OBJETIVOS ALCANZADOS: DIRECTRICES TERRITORIALES}

Las Directrices configuran los grandes ejes de la propuesta de ordenamiento territorial para la cuenca. La propuesta de directrices se realiza desde un enfoque sistémico, organizado en cuatro dimensiones de ordenamiento territorial -físico espacial, socio-económico, ecosistémica, e institucionalhabilitando así una lectura territorial más profunda y mayor comprensión de la complejidad del accionar de las cuatro dimensiones conjuntamente en el territorio: 
- Dimensión físico espacial. Jerarquizar, ampliar y mejorar el sistema de accesibilidad física (carreteras - vía férrea), asegurando la adecuada conectividad inter-micro regional -nacional y el fácil acceso terrestre o fluvial hacia las potenciales plataformas marítimas (Charqueada - La Paloma).

- Dimensión socio económica. Diversificar la producción, agregando valor a las actividades tradicionales (arroz, ganadería), favoreciendo la complementariedad producción y servicios asociados y una distribución de ingresos más equilibrada entre pequeños y grandes productores.

- Dimensión ecosistémica. Proteger los ecosistemas singulares y vulnerables, valorizar la diversidad y asegurar un uso racional, democrático y sustentable de los recursos naturales de la cuenca.

- Dimensión institucional. Profundizar la capacidad de gestión y participación de las instituciones departamentales y sociedades locales en los procesos de construcción del territorio, generar ámbitos que favorezcan la complementariedad interdepartamental, interinstitucional y regional

\section{Marco Jurídico Institucional}

Las bases de ordenamiento territorial y desarrollo sostenible formuladas para la cuenca del río Cebollatí y en especial las directrices territoriales enunciadas, se ajustan a los objetivos señalados por la LOTDS al concebir el ordenamiento del territorio, como la organización de sus usos, con la finalidad de mantener y mejorar la calidad de vida de la población, la integración social del territorio, y el uso y aprovechamiento ambientalmente sustentable y democrático de los recursos naturales y culturales.

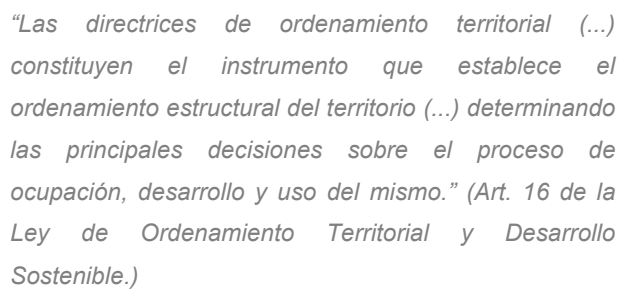


ID_I N VESTIG AC I O NES

La actividad académica realizada avanzó principalmente en la formulación de los siguientes instrumentos: directriz ${ }^{18}$ y el plan local.

Conforme a la LOTDS la directriz nacional es el instrumento general de la política pública en materia de ordenamiento territorial, configurando parte sustantiva de la misma sin pretender agotar su contenido ${ }^{19}$. Su objeto es múltiple e implica en síntesis la definición básica de la estructura territorial y la identificación de las actuaciones territoriales estratégicas como antecedente para los demás instrumentos de ordenamiento territorial, políticas sectoriales y proyectos de inversión pública con incidencia en la materia.

En lo que refiere al plan local, tiene por objeto ordenar los ámbitos geográficos locales dentro de un departamento ${ }^{20}$ rescatando las especificidades de dichos territorios.

\section{A MODO DE SÍNTESIS}

El trabajo "Cuenca del Cebollatí. Nuestro territorio...un proyecto compartido" es un estudio analítico-propositivo que reconoce a la cuenca del río Cebollatí como unidad territorial de actuación.

\footnotetext{
${ }^{18}$ Debemos tener presente que la L.O.T.D.S. menciona dos tipos de directrices: nacionales y departamentales, cuya diferencia sustancial radica en el órgano competente de sanción así como también

en el ámbito espacial de aplicación de la misma.
${ }^{9}$ Conjuntamente con los Programas Nacionales y las Estrategias Regionales, las Directrices Nacionales conforman "la tríada de instrumentos de ámbito nacional que han de estructurar la politica nacional de ${ }_{20}$ ordenamiento territorial y desarrollo sostenible". Su aprobación reviste forma de ley nacional.

${ }^{20}$ Se realizarán a iniciativa del Gobierno Departamental con la participación de las autoridades locales, las que definirán en cada caso su contenido, salvo cuando los contenidos del Plan Local estén indicados en
un instrumento de ordenamiento territorial del ámbito departamental.
} 


\section{ID INVESTIGACIONES}

El proceso de trabajo, lejos de ser lineal, aborda transversalmente las escalas planteadas, cuenca, microrregiones y localidades, reconociendo las peculiaridades territoriales de cada una de ellas.

La presente experiencia contribuirá a generar en sus habitantes la imagen de territorios compuestos por redes de localidades y de sentirse parte de sistemas territoriales más amplios que desbordan los límites jurídico-administrativos. Surge así la necesidad de que los actores territoriales trabajen las complementariedades locales en busca de estrategias colectivas para generar sinergias, y promover así el desarrollo local.

En este sentido, el material académico generado, podrá servir de insumo no solo para la elaboración de aquellos instrumentos mencionados expresamente en el convenio, directrices y planes locales, sino que además, configura un material de consulta para la confección de otros instrumentos previstos en nuestro sistema jurídico; en especial aquellos que involucran territorios pertenecientes a distintas jurisdicciones departamentales como estrategias regionales ${ }^{21}$ y planes interdepartamentales ${ }^{22}$.

Cabe destacar, el abordaje interinstitucional ,con participación activa de la academia conjuntamente con el gobierno nacional, departamental y la sociedad civil- e interdisciplinar, que apeló a los antecedentes académicos, así como también las vivencias de la población y experiencias de trabajo de autoridades locales y nacionales; y fomentó el intercambio de distintas disciplinas en la interna del equipo de trabajo.

\footnotetext{
${ }^{21}$ Por estrategias regionales se entienden los instrumentos de carácter estructural referidos al territorio nacional, que refieren a un área integrante de dos o más departamentos que precisan coordinación supradepartamental por compartir problemas y oportunidades en materia de desarrollo y gestión territorial. ${ }_{22}$ El plartanental por compartir problemas y oportunidades en materia de desarrollo y gestión territorial. pertenecientes a dos o más jurisdicciones departamentales -por ejemplo cuencas y ecosistemas pertenecientes a dos o más jurisdicciones departamentales -por ejemplo cuencas y ecosistemas compartidos y -a diferencia de las estrategias regionales- deberá ser formulado por acuerdo de los gobiernos departamentales involucrados y sometido a aprobación de los órganos legislativos departamentales respectivos. Se diferencian de los primeros no solo por su genesis, sino además porque involucrados.
} 


\section{ID_INVESTIGACIONES}

Finalmente, se debe expresar que la actividad realizada en la cuenca del Cebollatí es una expresión de la concepción de construcción de políticas de ordenamiento territorial desde la participación social, según el marco normativo vigente. Su producto es resultado de un proceso participativo desarrollado en varias instancias -talleres territoriales- en las que se construyó no solo un diagnóstico del territorio, sino que además se definieron objetivos a corto, medio y largo plazo y se enunciaron propuestas para la toma de decisiones futuras. Así comenzamos a transitar el camino para un aprendizaje colectivo de todas las partes implicadas, autoridades de gobierno, funcionarios de la administración pública, organizaciones sociales y sectoriales y vecinos no organizados, que sin duda, contribuirá a la legitimación social de los instrumentos de ordenamiento territorial y desarrollo sostenible que tomen como base este trabajo.

Esta experiencia ha permitido un acercamiento al territorio de la cuenca y a su gente, donde el aporte de todos y de cada uno de los participantes de los talleres ha sido imprescindible para el resultado final del presente trabajo.

El desarrollo de esta investigación, corre como el caudal de agua dulce que da la razón de ser a la misma, la cuenca del Cebollatí. En un país pequeño en superficie frente a sus pares sudamericanos, con una población de poco mas de 3 millones, donde la mitad de sus habitantes se distribuyen fuera de capital en bajísima densidad, donde colectar sus relatos, sus sentires, con historias escritas de una nación que comenzó a gestarse hace 200 años, aprender a ver los paisajes modelados debajo de los 500 metros de altura en todo el territorio, requiere un trabajo que linda con una acupuntura para tocar lo pequeño queriéndolo dejar intacto. Detectar esas diferencias es un aprendizaje que se hace de a poco y de a poco se aprende a usar esta nueva ley, para tenerla como herramienta y no como pretexto. 
ID_INVESTIGACIONES

\section{BIBLIOGRAFÍA PRINCIPAL}

ACHKAR, M., CAYSSIALS, R., DOMÍNGUEZ, A. y F., PESCE, (2004) "Hacia un Uruguay Sustentable: gestión integrada de cuencas hidrográficas”. Programa Uruguay Sustentable. REDES-AT. Montevideo. 64pp

ACUÑA, C. y otros (2009). Cuadernos "Talleres Territoriales de Maldonado. Construyamos el Territorio Departamental entre todos". IMM-ITU-Facultad de Arquitectura-Universidad de la República). Iconoprint, Montevideo.

ÁlVAREZ LENZI, R (1986) "Fundación de Poblados en el Uruguay". Instituto de Historia de la Arquitectura, Facultad de Arquitectura, UdelaR. Montevideo. 86pp

AROCENA J. (1998) "Propuesta metodológica para el estudio de desarrollo local". Serie Desarrollo Local en América Latina, v.1. CLAEH, Uruguay

ART (2008) "Diagnóstico Económico del Departamento de Treinta y Tres - Informe Enero/2008" Programa de Desarrollo Local. Montevideo 101pp. en http://www.arturuguay.org/art/home/fotos/395/infoeconomistas_tyt.pdf

BLANCO, I. y GOMÀ R. (coords.), (2002). "Gobiernos Locales y Redes Participativas". Editorial Ariel, Barcelona.

CLM (1970). "Plan de desarrollo de la Cuenca de la Laguna Merin" - Montevideo.

DINASA-FLACSO (2008). "Presentación sobre metodología de Planificación Participativa y Gestión Asociada". En el Seminario "Gestión Social del Agua en la Ciudad”. Montevideo.

INSTRUMENTOS Ley 18.308 y 18.367 de Ordenamiento Territorial y Desarrollo Sostenible.

LÓPEZ GALLERO, A. (1998). “Mevir Territorio y Comunidades”. En Revista Vivienda Popular $N^{\circ}$ 4. Rural. Facultad de Arquitectura.

MGAP. Sistema de Información Censo Agropecuario. SICA 2000. DIEA Estadísticas Agropecuarias.

NOGUÉ, J. (editor), (2007). "La construcción social del paisaje" Edit. Biblioteca Nueva, Madrid 343pp. 
ID_INVESTIGACIONES

OPP / IMTT: "Plan de Manejo Paisaje Protegido Quebrada de los Cuervos Treinta y tres Uruguay" Convenio OPP/IMTT-1998_IMTT, marzo 1998.

PÉREZ ARRARTE, C. y SCARLATTO, G. (2001) "La Cuenca de la Laguna Merín en Uruguay: de la defensa del patrimonio natural a una gestión para el desarrollo sustentable". En el Seminario Taller "Nuevas políticas ambientales. Sociedad y partidos políticos en la construcción del desarrollo alternativo". CLAES - FESUR. Montevideo, $13 p p$

PROBIDES, (1998). "Plan Director de la Reserva de Biosfera Bañados del Este”, Uruguay.

RODRÍGUEZ MIRANDA, A. y SIERRA, M. (2008) "Claves del desarrollo local. El caso de Treinta y Tres. Una metodología de análisis aplicada". Editorial: Fin de Siglo, Montevideo. $44 \mathrm{pp}$.

UNESCO (2007) “Agua y cultura” Proyecto UNESCO - Programa Hídrico Internacional -.

URRUZOLA, J.P., (2007). "Contribución a la crítica del territorio como materia ordenable. Cuadernos del territorio". Serie Tesis Convenio MVOTMA, UdelaR, Montevideo, Uruguay, $166 \mathrm{pp}$. 
ID_INVESTIGACIONES

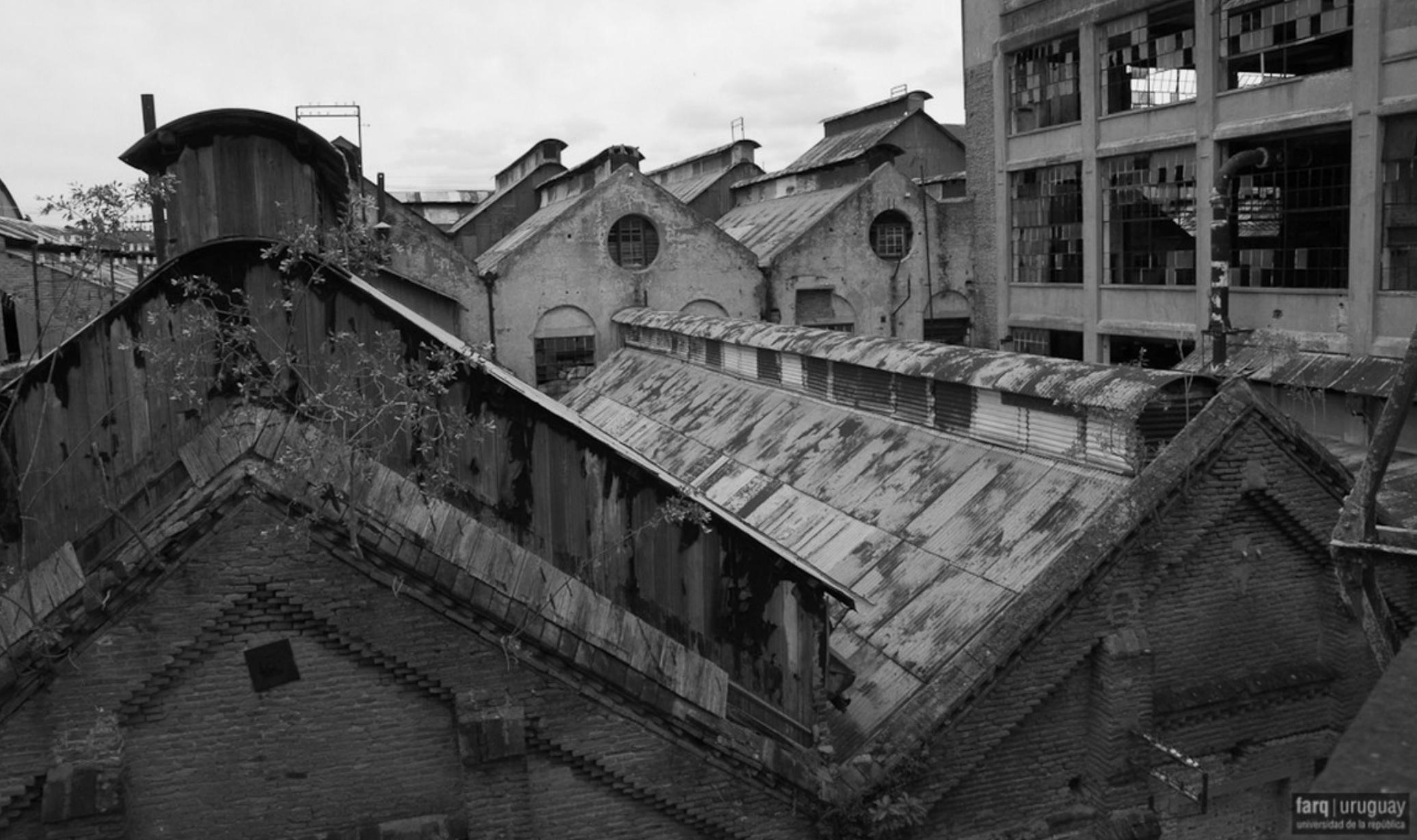

Frigorífico Anglo. Fuente: foto cedida por el Servicio de Medios Audiovisuales Facultad de Arquitectura, autora Silvia Montero 